\title{
Loss of Gata4 in Sertoli cells impairs the spermatogonial stem cell niche and causes germ cell exhaustion by attenuating chemokine signaling
}

\author{
Su-Ren Chen ${ }^{1}$, Ji-Xin Tang ${ }^{1,2}$, Jin-Mei Cheng ${ }^{1,2}$, Jian Li ${ }^{1,2}$, Cheng Jinn ${ }^{1,2}$, Xiao-Yu Li ${ }^{1,2}$, \\ Shou-Long Deng ${ }^{1}$, Yan Zhang ${ }^{1}$, Xiu-Xia Wang ${ }^{1}$ and Yi-Xun Liu ${ }^{1}$ \\ ${ }^{1}$ State key Laboratory of Stem Cell and Reproductive Biology, Institute of Zoology, Chinese Academy of Sciences, Beijing, \\ RP China \\ 2 University of the Chinese Academy of Sciences, Beijing, RP China \\ Correspondence to: Yi-Xun Liu, email: liuyx@ioz.ac.cn
}

Keywords: Gata4, spermatogonial stem cell, Sertoli cells, niche, chemokines, Pathology Section

Received: July 30, $2015 \quad$ Accepted: September 28, $2015 \quad$ Published: October 14, 2015

This is an open-access article distributed under the terms of the Creative Commons Attribution License, which permits unrestricted use, distribution, and reproduction in any medium, provided the original author and source are credited.

\section{ABSTRACT}

Sertoli cells, the primary somatic cell in the seminiferous epithelium, provide the spermatogonial stem cell (SSC) microenvironment (niche) through physical support and the expression of paracrine factors. However, the regulatory mechanisms within the SSC niche, which is primarily controlled by Sertoli cells, remain largely unknown. GATA4 is a Sertoli cell marker, involved in genital ridge initiation, sex determination and differentiation during the embryonic stage. Here, we showed that neonatal mice with a targeted disruption of Gata4 in Sertoli cells (Gata $4^{\text {flox/flox; }}$ Amh-Cre; hereafter termed Gata 4 cKO) displayed a loss of the establishment and maintenance of the SSC pool and apoptosis of both gonocyte-derived differentiating spermatogonia and meiotic spermatocytes. Thus, progressive germ cell depletion and a Sertoli-cell-only syndrome were observed as early as the first wave of murine spermatogenesis. Transplantation of germ cells from postnatal day 5 (P5) Gata 4 cKO mice into Kit ${ }^{\mathrm{w} / \mathrm{W}-\mathrm{v}}$ recipient seminiferous tubules restored spermatogenesis. In addition, microarray analyses of P5 Gata 4 cKO mouse testes showed alterations in chemokine signaling factors, including CXCl12, Ccl3, CXCr4 (CXCL12 receptor), CCr1 (CCL3 receptor), Ccl9, $X \mathrm{Cl} 1$ and $\mathrm{Ccr} / 2$. Deletion of Gata 4 in Sertoli cells markedly attenuated Sertoli cell chemotaxis, which guides SSCs or prospermatogonia to the stem cell niche. Finally, we showed that GATA4 transcriptionally regulated $\mathrm{CxCl12}$ and $\mathrm{Cc} / 9$, and the addition of CXCL12 and CCL9 to an in vitro testis tissue culture system increased the number of $\mathrm{PLZF}^{+}$undifferentiated spermatogonia within Gata4 cKO testes. Together, these results reveal a novel role for GATA4 in controlling the SSC niche via the transcriptional regulation of chemokine signaling shortly after birth.

\section{INTRODUCTION}

Approximately $50 \%$ of human infertility is attributable to male defects, of which $70-90 \%$ stem from impaired spermatogenesis [1]. The process of spermatogenesis can be divided into three phases: mitotic proliferation of spermatogonia, meiotic division of spermatocytes and morphologic differentiation of haploid spermatids during spermiogenesis. Mouse spermatogenesis is initiated only a few days after birth and proceeds in a synchronized manner [2]. Key time points regarding the appearance of particular germ cell types are well defined during the first cycle of spermatogenesis $[3,4]$. Postnatal day (P) 5-7 mouse testes contain only Sertoli cells and gonocyte-derived spermatogonia in the seminiferous tubules. Early spermatocytes appear at P9, the pachytene stage of the first meiotic prophase is initiated at P14, round spermatids are generated at P20, and condensing spermatids are created by P30 [3, 5].

Spermatogenesis requires the proper regulation of spermatogonial stem cells (SSCs) to replenish the testis 
with germ cell progenitors during adult life. Sertoli cells, the primary somatic cell type in the seminiferous epithelium, directly interact with SSCs to control their proliferation and differentiation through the secretion of specific factors (reviewed in [6]). Glial cell line-derived neurotrophic factor (GDNF), which is secreted by Sertoli cells, is a well-defined paracrine factor that promotes SSC self-renewal and maintenance in the niche [7]. Supplementation with fibroblast growth factor 2 (FGF2, also known as basic FGF (bFGF)), which is also secreted by Sertoli cells, in combination with GDNF allows for the long-term self-renewal and expansion of SSCs [8]. CXCL12 encodes a chemokine that is expressed and secreted by Sertoli cells and binds to the CXCR4 receptor on SSCs to regulate their self-renewal and maintenance [9]. Chen et al. demonstrated that Ets-related molecule (ERM; also known as ETV5) is primarily expressed by Sertoli cells and is required for SSC self-renewal because it regulates several chemokine genes, including CXCL12, CXCL5, and CCL7 $[10,11]$. However, apart from these involved genes, the mechanisms by which Sertoli cells regulate the SSC niche are largely unknown.

The GATA transcription factor family consists of six members (GATA1-6). The members share the highest homology in the zinc finger DNA-binding domain, and they all bind to the consensus site (T/A)GATA $(A / G)$. Many Sertoli cell-specific genes have GATA-binding sites in their promoters [12]. Lindeboom et al. suggested that GATA1 in Sertoli cells is not essential for murine testis development or spermatogenesis [13].

GATA4 is an evolutionarily conserved zinc finger transcription factor that is essential for the early development of multiple organs, including the heart, foregut, liver, and pancreas [14-16]. GATA4 is predominantly expressed in somatic cells within the testis (Sertoli cells, Leydig cells and other interstitial cells), and its expression remains consistently abundant in both embryonic gonads and adult testes. Recently, $\mathrm{Hu}$ et al. suggested that mouse embryos that were conditionally deficient for Gata4 showed no signs of gonadal initiation [17]. In XY transgenic mice harboring mutant GATA4 $\left(\right.$ Gata $\left.4^{k i}\right)$ that abrogates GATA4 binding to the co-factor FOG2 (Friend of GATA), genital ridges formed, but the subsequent differentiation into testes was blocked, and SRY (Sex Determining Region, Y Chromosome) expression was attenuated [18]. Mouse embryos that were heterozygous for Gata $4^{k i}$ in specific genetic backgrounds also showed sex reversal from genetic males to phenotypic females [19]. An in vitro study further suggested that GATA4 and WT1 (Wilms' Tumor 1) synergistically activate the transcription of Sry [20]. Manuylov et al. suggested that GATA4 regulates testicular differentiation. The excision of Gata 4 by $W t 1^{\text {CreERT2 }}$ at E10.5 led to an early and broad failure of Sertoli cell differentiation and male development with concurrent sex reversal. Furthermore, Sf1-Cre-mediated excision of Gata4 at E12.5 led to testis cord defects and a loss of Dmrt1 gene expression in Sertoli cells [21].

The critical role of GATA4 in human gonadal development is highlighted by a familial case of 46, XY DSD (Disorder of Sex Development) associated with a heterozygous GATA4 p.Gly221Arg mutation [22]. The p.Gly221Arg mutant protein fails to bind to FOG2 and disrupts the synergistic activation of the $A M H$ promoter. Recently, Bashamboo et al. identified three missense mutations (p.S402R, p.R260Q and p.M544I) in FOG2, which abolished the interaction with GATA4, in two patients with 46, XY DSD [23].

Collectively, previous studies suggest that GATA4 is essential for proper fetal testis development. Here, we extended these findings by determining the effects of GATA4 expression in Sertoli cells in the postnatal testes. This study was accomplished by crossing Amh-Cre knockin mice with Gata4 $4^{\text {flox/lox }}$ mice. Gata 4 cKO males exhibited few GFRA1 ${ }^{+}$and $\mathrm{PLZF}^{+}$(also known as ZBTB16) undifferentiated spermatogonia (including SSCs) after birth. Markers of differentiating spermatogonia (c-KIT) and meiotic spermatocytes (STRA8) exhibited normal expression, indicating 'normal' spermatogenic differentiation of gonocyte-derived differentiating spermatogonia in Gata4 cKO testes; however, these cells ultimately underwent apoptosis. During the first wave of spermatogenesis, the mutant testes exhibited an extensive loss of germ cells, including SSCs, followed by a Sertolicell-only syndrome. Interestingly, the transcriptional levels of many chemokine signaling molecules were significantly reduced in the Gata 4 cKO testes. Furthermore, we showed that GATA4 transcriptionally regulated $\mathrm{Cxcl12}$ and $\mathrm{Ccl} 9$ in Sertoli cells. The addition of CXCL12 and CCL9 to an in vitro testis tissue culture system significantly increased the number of $\mathrm{PLZF}^{+}$undifferentiated spermatogonia in Gata 4 cKO males. Collectively, we conclude that GATA4 in Sertoli cells governs the establishment and maintenance of a SSC niche by regulating chemokine signaling.

\section{RESULTS}

\section{Sertoli cell-specific knockout of Gata4 results in a complete loss of germ cells}

To investigate the role of GATA4 expression in Sertoli cells during postnatal testicular development and spermatogenesis, we generated a Sertoli cell-specific Gata4 knockout mouse line (Gata4 flox/flox, Amh-Cre, hereafter referred to as Gata4 cKO) by crossing a Sertoli cell-specific Cre line (Amh-Cre) with a Gata4-loxP line (Figure 1A-1C). In neonatal Gata4 cKO mice, GATA4 was specifically inactivated in Sertoli cells, as evidenced by Western blot (Figure 1D) and immunohistochemistry (Figure 1E). The fertility of the male mice was assessed 
by mating 6- to 8-week-old male Gata4 $\mathrm{cKO}$ and their control littermates with wild-type (C57BL/6) females over a 3-month period. As shown in Figure 1F, the Gata 4 cKO male mice were completely infertile. An examination of juvenile and adult male testes revealed no difference in fresh tissue size at postnatal day 1 (P1); however, the testes from Gata4 cKO males at P7 or older were significantly smaller, such that by adulthood (6 weeks of age), the Gata 4 cKO testes had dramatically shrunk (Figure 1G). The testis weight of Gata $4 \mathrm{cKO}$ males was significantly lower than that of wild-type males at P7, 3 weeks and 6 weeks (Figure 1H). Histological examination of 6-weekold Gata $4 \mathrm{cKO}$ testes revealed that all of the tubules were devoid of germ cells and contained only morphologically
A
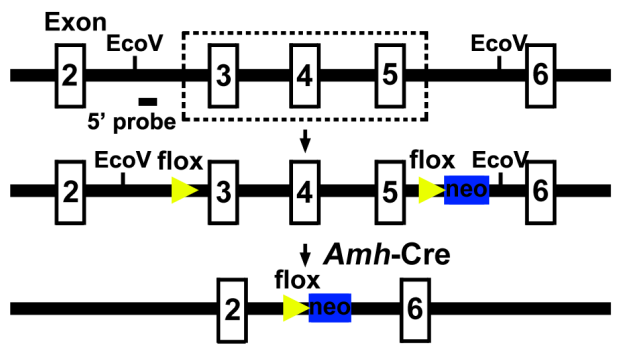

B

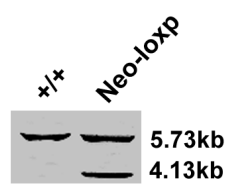

C

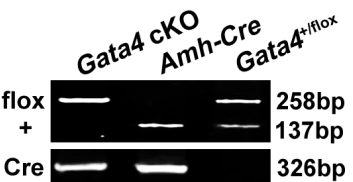

D

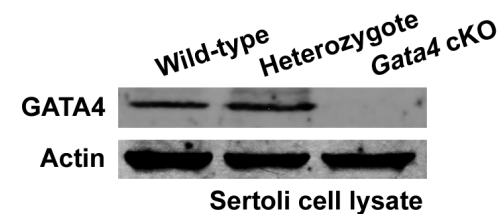

E

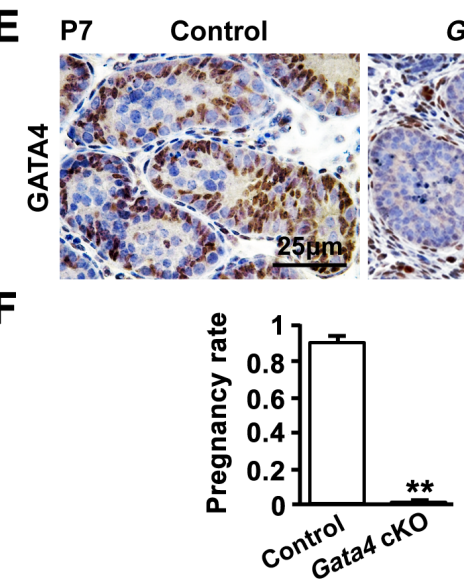

G

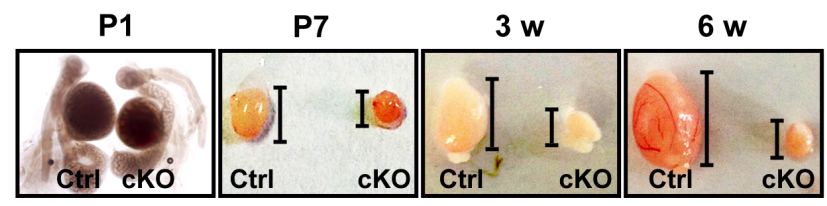

H
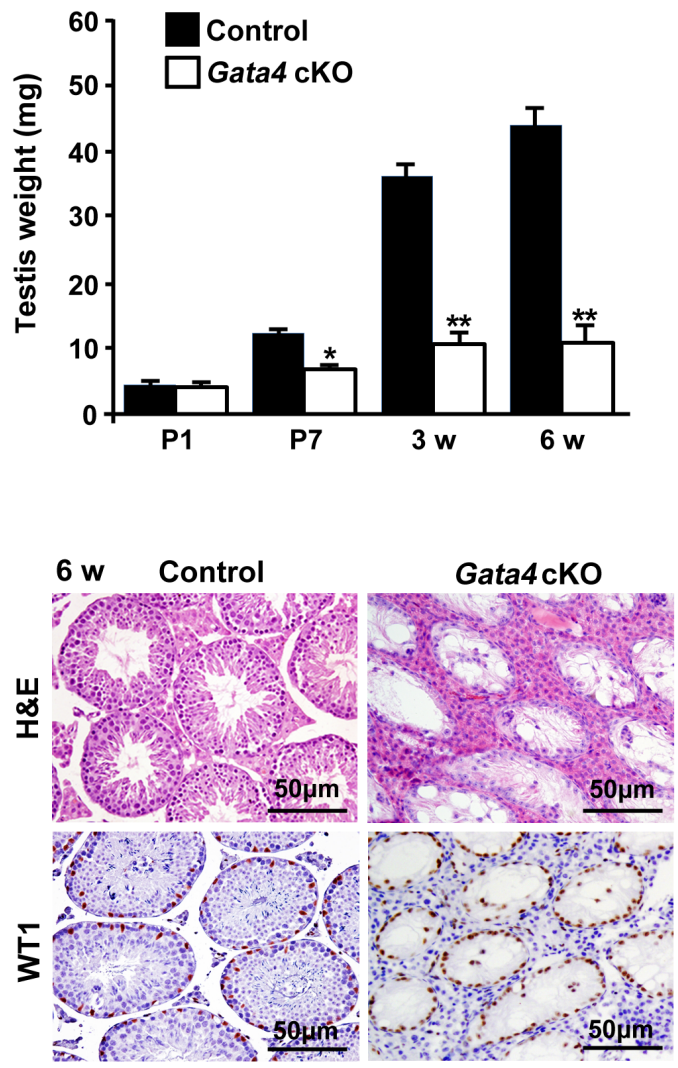

Figure 1: Conditional deletion of Gata4 in Sertoli cells using Amh-Cre. A. Structures of the floxed (Gata4 $\left.{ }^{\text {flox }}\right)$ and null (Gata4 cKO) Gata4 alleles after Amh-Cre-mediated recombination. Yellow triangles represent loxP cassettes, and blue rectangles depict neo sites. The exons are numbered. B. Southern blot: EcoRV-digested ES cell DNA probed with a 5' probe yielded a $5.73 \mathrm{~kb}$ fragment in recombinant animals in addition to the wild-type $4.13 \mathrm{~kb}$ fragment, confirming the insertion of the targeting construct into the Gata 4 locus. C. Genotyping via PCR. PCR analysis of the presence of the floxed and wild-type Gata4 alleles. An analysis of the presence of Cre in the Amh-Cre transgene is shown below. The product size is listed. D. Western blot analysis of GATA4 in isolated Sertoli cell extracts from neonatal wild-type, heterozygous and Gata4 $\mathrm{cKO}$ mice. Actin served as a protein loading control. E. Immunohistochemical staining of GATA4 in wild-type and Gata4 cKO testes. Note that the GATA4 signal (brown) was specifically deleted in the Sertoli cells of Gata4 cKO testes. Scale bar, $25 \mu \mathrm{m}$. F. Fertility test: $95.01 \pm 1.46 \%$ of the plugged females were pregnant after crossing with Gata $4^{\text {flox } / \text { flox }}$ control males, whereas none of the plugged females were pregnant after crossing with Gata 4 cKO males. The data are expressed as the mean \pm S.D. $(n=$ 10 per genotype). ${ }^{* *} p<0.01$. G. Gross morphology in control (left) and Gata 4 cKO (right) testes at P1, P7, 3 w and 6 w. H. Histograms of testis weight in control and Gata $4 \mathrm{cKO}$ mice $(\mathrm{mg})$. The data are expressed as the mean \pm S.D. ( $n=6$ per genotype). ${ }^{*} p<0.05, * * p<0.01$. I. H\&E staining and immunohistochemistry of WT1 (a Sertoli cell marker; brown signals) in testes from control and Gata4 cKO mice at $6 \mathrm{w}$. Scale bar, $50 \mu \mathrm{m}$. 
normal Sertoli cells (Figure 1I).

\section{Sertoli-cell-only phenotype occurs as early as the initial wave of spermatogenesis}

To track the key moments of spermatogenic failure, we investigated testicular morphology at four time points during the first wave of murine spermatogenesis. At P3, the seminiferous tubules of control and Gata4 cKO mice appeared similar, with WT1-positive Sertoli cells and MVH-positive germ cells indicating the normal initiation of spermatogenesis (Figure 2A-2E). At P7, the germ cells within control testes had migrated to the basement membrane. In contrast, the germ cells of Gata4 cKO testes remained aligned at the luminal side of the testicular tubules, indicating that they had lost the ability to locate the niche (Figure 2F-2J). Subsequently, we observed a phenotype corresponding to an age-dependent loss of germ cells in Gata 4 cKO testes. By 3 weeks, Gata 4 cKO tubules exhibited vacuolization, and no germ cells remained attached to the basement membrane (Figure 2K-
2O), indicating exhaustion of the SSC pool. Consequently, Gata 4 cKO testes were entirely devoid of germ cells by 4 weeks, forming a Sertoli-cell-only phenotype (Figure 2P-2T). Accordingly, we concluded that spermatogenesis was completely disrupted as early as the first wave in Gata4 cKO testes. We speculate that GATA4 plays a critical role in the establishment and/or maintenance of the spermatogonial progenitor pool.

\section{Failure to establish and maintain the SSC pool in Gata4 cKO testes}

To further explore the premature exhaustion of the spermatogonia progenitor pool in Gata4 cKO testes, we measured the abundance of undifferentiated spermatogonia at P7 by staining histological sections and whole-mount tubules for PLZF and GFRa1. PLZF is expressed at all stages in undifferentiated spermatogonia, whereas GFRa1 is expressed primarily in $\mathrm{A}_{\text {single }}$ (so-called SSCs) and $\mathrm{A}_{\text {pared }}$ spermatogonia [24-26]. At P7, the density of GFRa1 ${ }^{+}$ spermatogonia was significantly decreased in Gata4 cKO

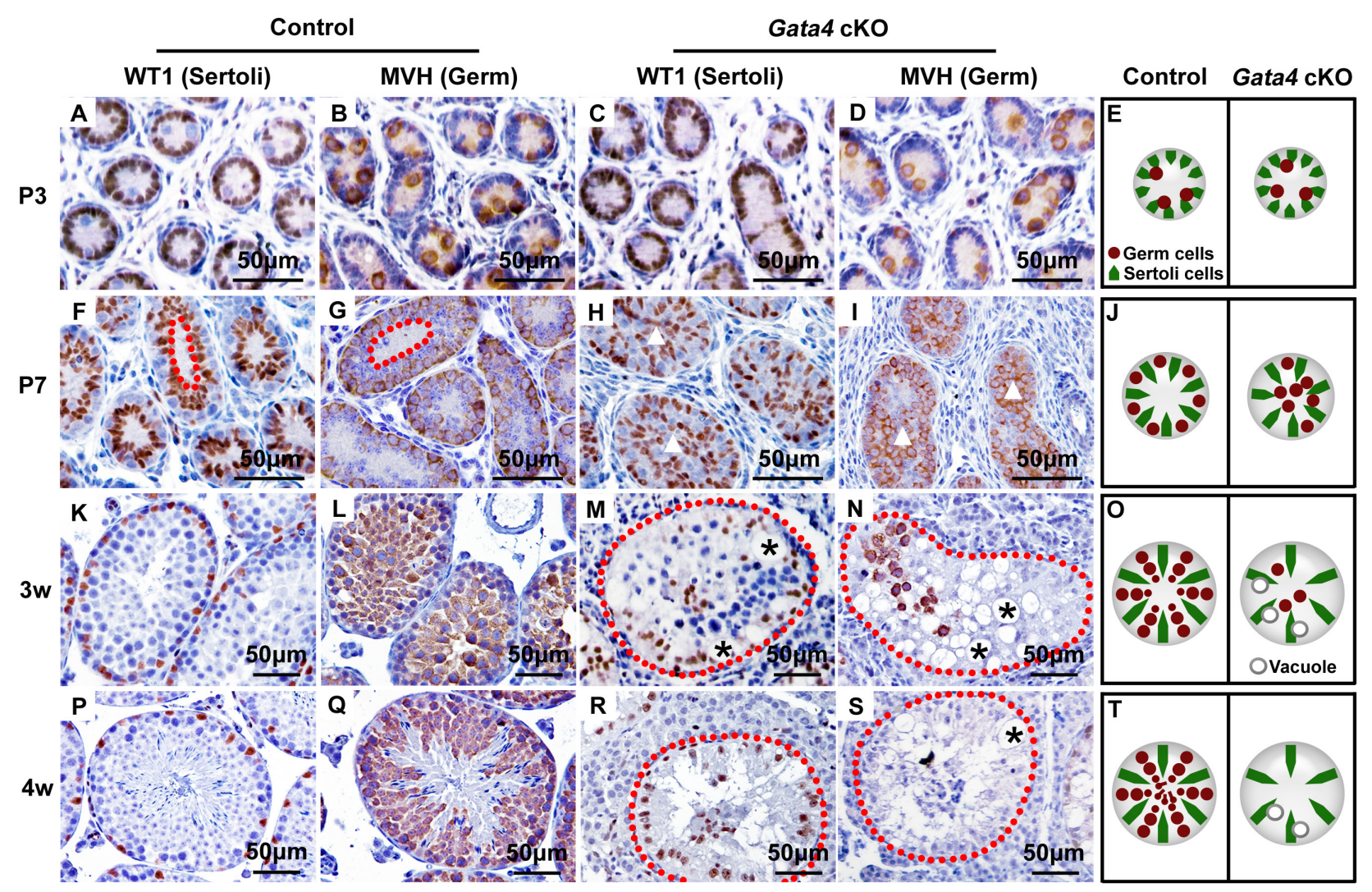

Figure 2: Morphological change at P7 and Sertoli-cell-only syndrome at $4 \mathbf{w}$ in Gata4 cKO testes. A. Representative seminiferous tubule morphology at P3 A.-D., P7 F.-I., 3 w K.-N. and 4 w P.-S. with immunohistochemical staining of WT1 (a Sertoli cell marker, brown) and MVH (a germ cell marker, brown). The nuclei are stained blue with hematoxylin. The red dotted lines in F. and $\mathbf{G}$. indicate the lumen formed by the localization of germ cells to the basement membrane in control testes. The white triangles in $\mathbf{H}$. and $\mathbf{I}$. indicate that no lumen formed in Gata4 cKO testes. The red dotted lines in M., N., R. and S indicate the borders of the testicular tubules. The black stars in M., N. and S indicate vacuoles. E., J., Q. and T. are cartoons that depict the differing morphologies of testicular tubules in control and Gata4 cKO testes. Scale bar, $50 \mu \mathrm{m}$. 
testes compared to control testes (Figure 3A, 3B, 3G-3I). Similarly, $\mathrm{PLZF}^{+}$spermatogonia were rare in Gata4 cKO tubules but abundant in age-matched controls (Figure 3C, 3D). Upon mitotic division, SSCs can self-renew to maintain the spermatogonia progenitor pool. Next, a BrdU incorporation assay was conducted to test the self-renewal characteristics of the extremely insufficient population of $\mathrm{GFRa}^{+}$spermatogonia in P7 Gata4 cKO testes. We found that approximately $28 \%$ of the GFRa $1^{+}$spermatogonia incorporated BrdU in control testes, whereas no GFRa1 ${ }^{+} /$ $\mathrm{BrdU}^{+}$spermatogonia were observed in Gata $4 \mathrm{cKO}$ testes (Figure 3J). Collectively, these data suggest that neither the establishment nor the maintenance of the SSC pool is appropriately regulated in Gata4 cKO testes.

\section{Fate of gonocyte-derived differentiating spermatogonia during the first wave of spermatogenesis in Gata4 cKO testes}

During the first wave of spermatogenesis, gonocytes can directly give rise to differentiating spermatogonia (unique in the first wave of spermatogenesis) and SSCs in parallel [2] (Figure 4A). As SSCs exhibited defects in both establishment and maintenance in Gata4 cKO testes (Figure 3), we examined the fate of the gonocytederived differentiating spermatogonia in Gata4 $\mathrm{cKO}$ testes. c-KIT staining of differentiated spermatogonia
(Figure 4B) and STRA8 staining of meiotic spermatocytes (Figure 4C) were similar in control and Gata 4 cKO testes at P9, suggesting that the differentiation of gonocytederived differentiating spermatogonia was not disrupted by GATA4 deletion in Sertoli cells. Furthermore, double immunofluorescence staining of meiosis-associated markers, such as $\gamma$-H2AX and SYCP3, was performed at 2 weeks. As shown in Figure 4D, spermatocytes in the pachytene stage were observed in both control and Gata4 cKO tubules. In addition, Western blotting showed that the protein levels of PLZF and GFRa1 were significantly reduced, while the expression of c-KIT, STRA8 and SYCP3 was not altered in Gata4 cKO testes compared to control testes (Figure S1). To determine whether massive spermatocyte cell death led to the exhaustion of germ cells in Gata4 cKO testes, we assayed apoptosis via a TUNEL assay at 3 weeks. As expected, massive germ cell apoptosis was observed in Gata4 cKO tubules (Figure 4E).

\section{Transplantation of germinal cells from Gata 4 cKO donors into $\mathrm{Kit}^{\mathrm{W} / \mathrm{W}-\mathrm{v}}$ recipients}

Because GATA4 mutation leads to male sterility [22], we attempted to rescue the infertile phenotype of the Gata4 cKO mice and thereby identify potential new leads for the treatment of infertile patients carrying a GATA4 mutation. We transplanted germinal cells from 5-day-
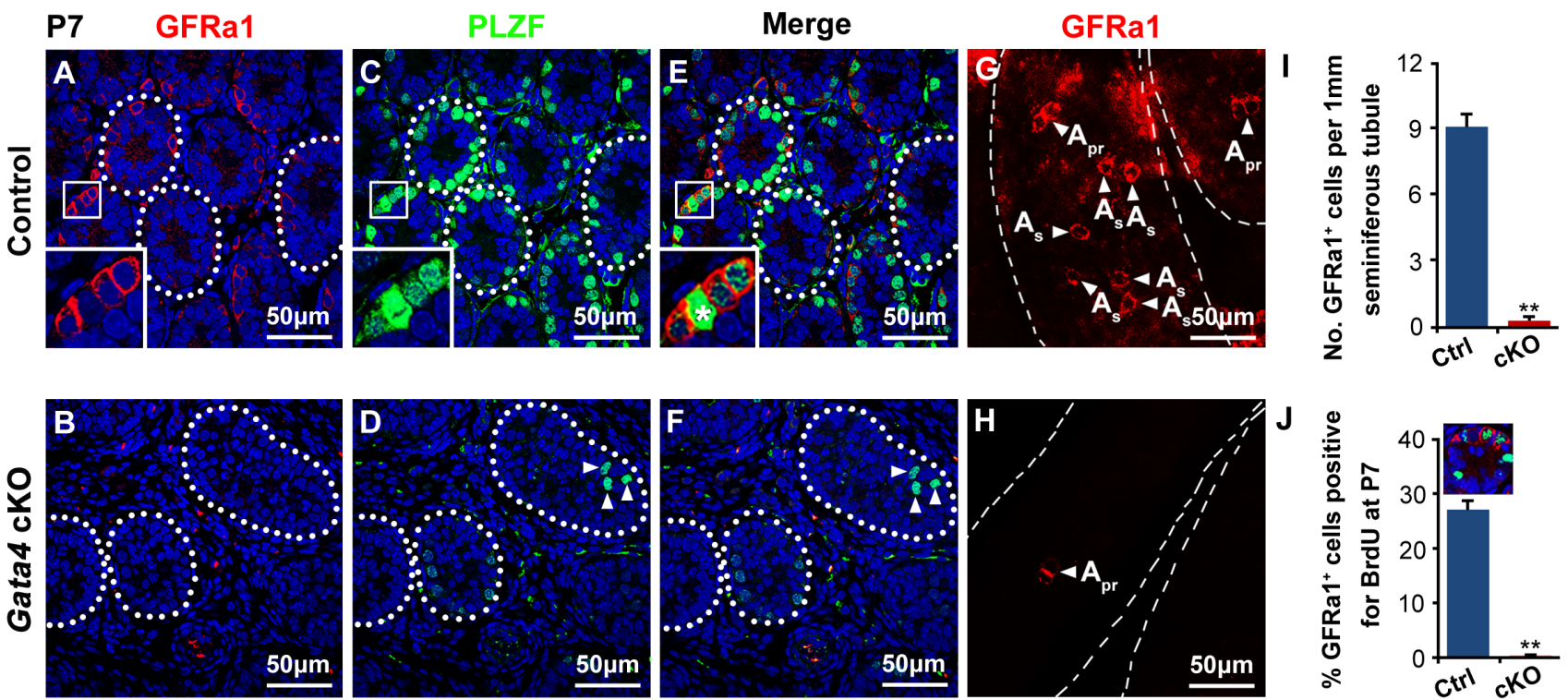

Figure 3: Few GFRa1 ${ }^{+}$or PLZF ${ }^{+}$spermatogonial progenitors within the Gata4 cKO testes. A., B. Testis sections from control and Gata4 cKO mice at P7 were probed with antisera against GFRa1 (red). The nuclei are counterstained with DAPI (blue). C., D. Immunofluorescence staining for PLZF (green) in control and Gata4 cKO testis sections at P7. The white arrowheads in D. indicate the low number of $\mathrm{PLZF}^{+}$spermatogonia within Gata $4 \mathrm{cKO}$ testes. The white dotted lines indicate the testicular tubules. Scale bar, $50 \mu \mathrm{m}$. E. and $\mathbf{F}$. are the merged images of $\mathrm{A}+\mathrm{B}$ and $\mathrm{C}+\mathrm{D}$, respectively. G., H. Representative images of staining for GFRa1 (red)-expressing cells in a whole-mount seminiferous tubule at P7. The white arrowheads indicate $\mathrm{A}_{\text {single }}$ and $\mathrm{A}_{\text {paired }}$ spermatogonia according to their morphology. I. Density of GFRa $1^{+}$spermatogonia per $1 \mathrm{~mm}$ in seminiferous tubules of the control and Gata $4 \mathrm{cKO}$ testes $(n=3$ each). The data are expressed as the mean \pm S.D. ${ }^{* *} p<0.01$. J. BrdU-labeling index of GFRa1 ${ }^{+}$spermatogonia in control and Gata $4 \mathrm{cKO}$ testes at P7. BrdU was injected $4 \mathrm{~h}$ before the mice were sacrificed. The data are expressed as the mean \pm S.D. ${ }^{* *} p<0.01$. 
old control and Gata4 cKO testes into the seminiferous tubules of $K i t^{\mathrm{W} / \mathrm{W}-\mathrm{v}}$ mice (Figure $5 \mathrm{~A}$ ). The testes of $K i t^{\mathrm{W} / \mathrm{W}-\mathrm{v}}$ mice are hospitable to donor cell colonization because they lack endogenous germ cells and have functionally normal Sertoli cells (Figure 5B). We showed that the transplanted germinal cells from control (Figure 5C) and Gata4 cKO (Figure 5D) males differentiated into MVH-positive spermatocytes and round spermatids in the seminiferous tubules of $K i t^{\mathrm{W} / \mathrm{W}-\mathrm{v}}$ recipient mice after transplantation. In addition, TRS4-positive round and elongating spermatids were aligned at the luminal side of the seminiferous tubules in $K i t^{\mathrm{W} / \mathrm{W}-\mathrm{v}}$ recipient testes by 8 weeks after transplantation. Offspring were produced from germ cells from transplanted $K i t^{\mathrm{W} / \mathrm{W}-\mathrm{v}}$ recipient males via in vitro microinsemination (Figure 5E). These results suggested that GATA4 functions in Sertoli cells to establish the proper microenvironment for spermatogenesis and that transplantation provides an approach for restoring fertility in Gata4 cKO males.

\section{Deletion of Gata4 in Sertoli cells markedly attenuates Sertoli cell chemotaxis}

To explore the reasons for the impaired SSC niche in Gata 4 cKO testes, we conducted a microarray analysis to compare gene expression between control and Gata $4 \mathrm{cKO}$ testes at P5, when the testes of the two phenotypes have an identical histological appearance. These analyses revealed significant (at least 2-fold) increases in the abundance of 64 transcripts and decreases in the abundance of 68 transcripts in Gata4 cKO testes compared to control testes (Table S3, S4). Based on pathway term analysis, the most significant functions associated with the differentially
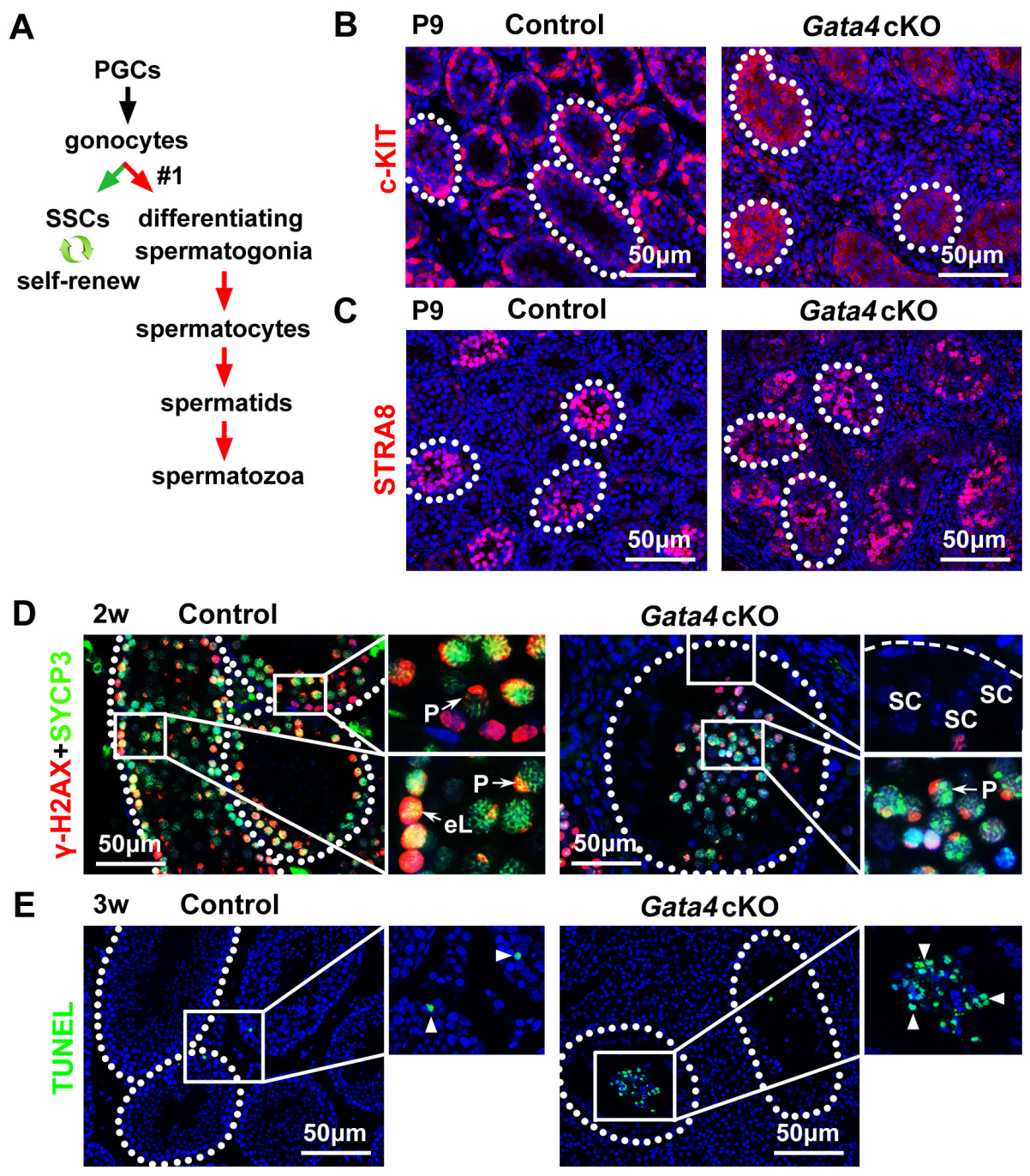

Figure 4: Differentiation of gonocyte-derived differentiating spermatogonia but subsequent apoptosis of meiotic spermatocytes in Gata4 cKO testes. A. Model for the two lineages in murine spermatogenesis: gonocyte-derived undifferentiated spermatogonia (also named SSCs) and gonocyte-derived differentiating spermatogonia. The distribution of c-KIT B. and STRA8 C. in testes from control and Gata $4 \mathrm{cKO}$ mice at P9. D. $\gamma$-H2AX (red) and SYCP3 (green) immunostaining of control and Gata4 $\mathrm{cKO}$ testes at 2 w. eL, early leptotene; P, pachytene; SC, Sertoli cells. E. A TUNEL assay was performed to detect apoptotic cells (green; arrowheads) in control and Gata 4 cKO testes at 3 w. The white dotted lines in B.-E. indicate the testicular tubules. Scale bars in B.-E., $50 \mu \mathrm{m}$. 
expressed genes in Gata4 cKO testes were chemotaxis, cell apoptosis, Sertoli cell transcription factor, cell adhesion and extracellular matrix, fatty acid metabolism and RA metabolism. Notably, the expression of many genes involved in chemokine signaling, including Cxcl12, Ccl3, Ccl9, Cxcr4, Ccrl, Xcl1 and Ccrl2, was significantly down-regulated following Gata4 gene deletion (Figure 6A). Cxcl12, Ccl3, Ccl9, Xcll and Ccrl2 were expressed in Sertoli cells, while Cxcr4 and Ccrl were present in germ cells (Figure S2). The microarray results were confirmed by RT-PCR analysis of testes from P5 control and Gata4 cKO littermates (Figure 6B). To further evaluate the expression of CXCL12, CXCR4 (CXCL12 receptor), CCL9 and CCR1 (CCL9 receptor) in the developing testis, we conducted double immunofluorescence staining of P5 mouse testis sections using specific antibodies. In wild- type testes, CXCL12 and CCL9 staining was observed within the cytoplasm of Sertoli cells, and their receptors CXCR4 and CCR1 were localized at the surface of spermatogonia (Figure 6C-a, c). In contrast, the expression of these chemokines and their receptors was markedly reduced in age-matched Gata $4 \mathrm{cKO}$ testes (Figure 6C-b, d).

Because CXCL12 and CCL9 facilitate Sertoli cell chemoattraction of spermatogonia by binding to CXCR4 and CCR1 on the surface of spermatogonia [6,9], we speculated that Sertoli cells in Gata 4 cKO testes would have decreased chemotactic activity. Thus, we analyzed the chemotactic index, which was defined as the number of spermatogonia (or other germ cells) that had migrated toward Sertoli cells. This index was significantly decreased for the migration of germ cells from P5 males toward
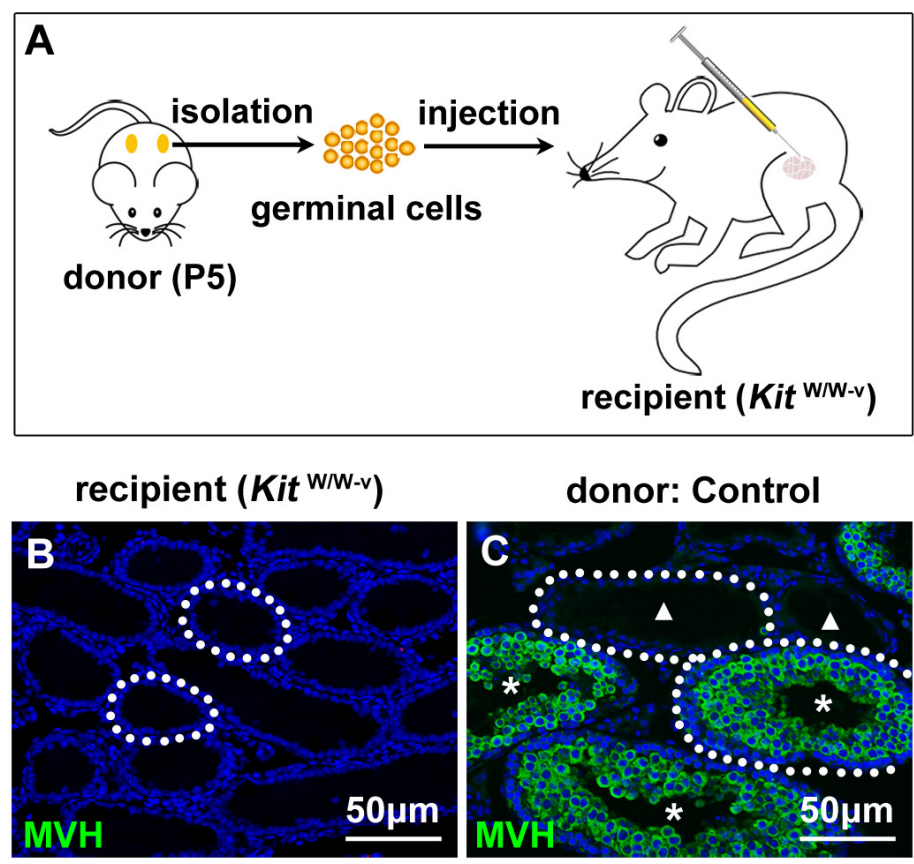

donor: Gata4 cKO
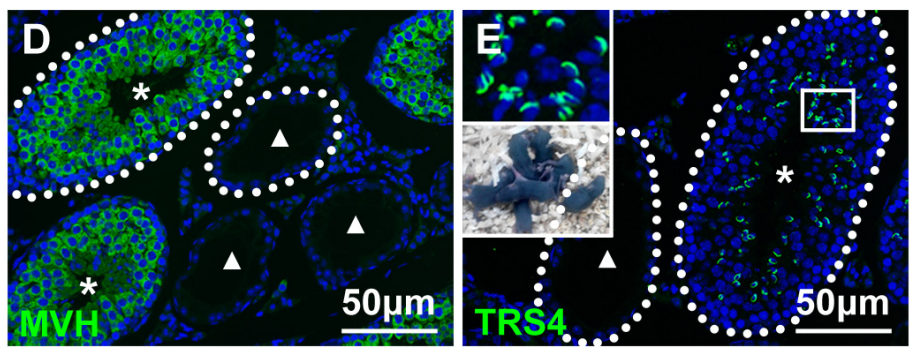

Figure 5: Histological images of seminiferous tubules in recipient mouse testes after transplantation of germinal cells from P5 Gata4 cKO males. A. Schematic of the germinal cell transplantation strategy. B. Histological section of Kit ${ }^{\mathrm{W} / \mathrm{W}-\mathrm{v}}$ recipient seminiferous tubules stained with an anti-MVH antibody (green). Representative images of MVH immunostaining (green) of Kit ${ }^{\mathrm{W} / \mathrm{W}-\mathrm{v}}$ recipient seminiferous tubules after transplantation with donor germinal cells from control C. and Gata4 cKO males D. Stars and triangles indicate colonized and noncolonized seminiferous tubules after transplantation, respectively. E. A testicular cross section of $\mathrm{Kit}^{\mathrm{W} / \mathrm{W}-\mathrm{v}}$ recipient testes at $8 \mathrm{w}$ after transplantation of donor germinal cells from Gata $4 \mathrm{cKO}$ males stained with an anti-TRS4 antibody (green) to show the acrosome. The transplanted $\mathrm{Kit}^{\mathrm{W} / \mathrm{W}-\mathrm{v}}$ recipient males reproduced spermatozoa with acrosome (above) and generated progeny (below). The cell nuclei are stained with DAPI (blue). The white dotted lines indicate the testicular tubules. Scale bars in B-E, $50 \mu \mathrm{m}$. 
Gata4-deficient Sertoli cells compared to control Sertoli cells (Figure 6D). This result indicated that Gata4 deletion in Sertoli cells markedly attenuated the ability of Sertoli cells to chemotactically guide SSCs or prospermatogonia to the stem cell niche.

\section{Regulation of CXCL12 and CCL9 by GATA4 in Sertoli cells}

To determine whether the attenuated expression of CXCL12 and CCL9 caused the defect in the SSC niche in Gata 4 cKO testes, P3 testis explants from Gata $4 \mathrm{cKO}$ males were cultured in vitro, and chemokines (CXCL12 and/or CCL9) were added to the culture medium (Figure 7A). After a 4-day culture, the number of PLZF undifferentiated spermatogonia was significantly higher after the addition of CXCL12, CCL9, or both. Moreover, the number of $\mathrm{PLZF}^{+}$undifferentiated spermatogonia was significantly higher after treatment with CXCL12 and CCL9 than after treatment with CXCL12 or CCL9 individually (Figure 7B). Although some spermatogonia remained aligned at the luminal side in some testicular tubules (white triangle), the number of undifferentiated spermatogonia in Gata4 cKO testes was comparable to that in control testes due to the addition of CXCL12 or CCL9 (Figure 7C-b). After 4 weeks in culture, some seminiferous tubules from chemokine-treated Gata $4 \mathrm{cKO}$ testes contained germ cells arrested as spermatocytes (triangle) and other tubules were devoid of germ cells (stars) (Figure 7C-c).

To determine whether GATA4 regulates the gene expression of $\mathrm{Cxcl1} 2$ and $\mathrm{Ccl} 9$ in Sertoli cells, we isolated and cultured primary Sertoli cells and then evaluated or attenuated the endogenous GATA4 levels via adenoviral overexpression of GATA4 or transfection with a GATA4binding site mutant (Gata4 ${ }^{\text {Cys294Ala }}$ ) plasmid, respectively. Similar to the well-established GATA4-targeted gene Dmrt1, the mRNA levels of Cxcl12 and Ccl9 were significantly up-regulated after GATA4 adenovirus
A

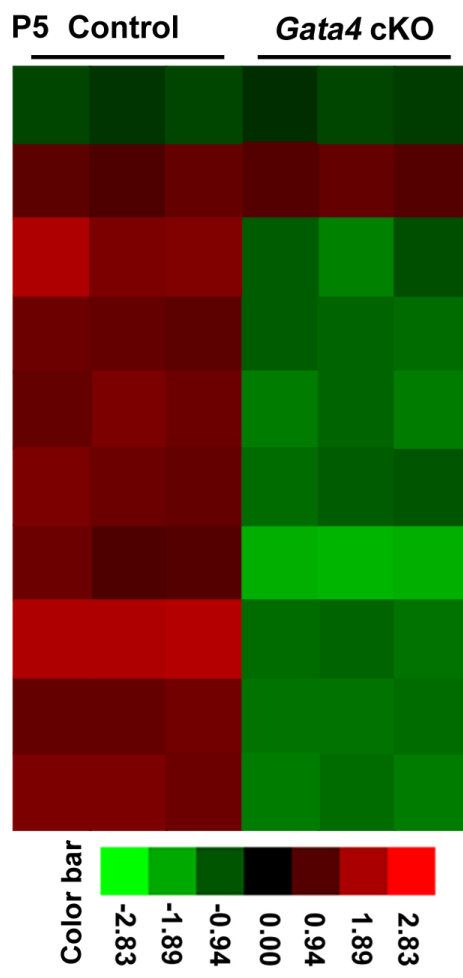

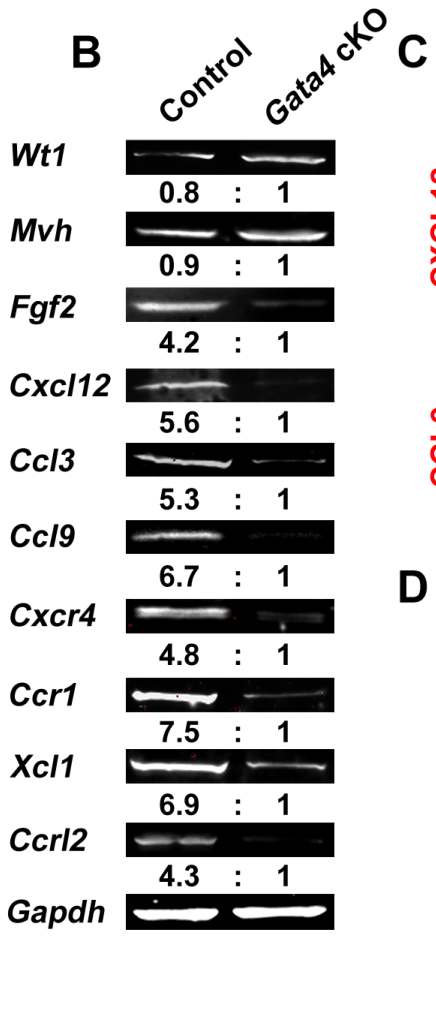

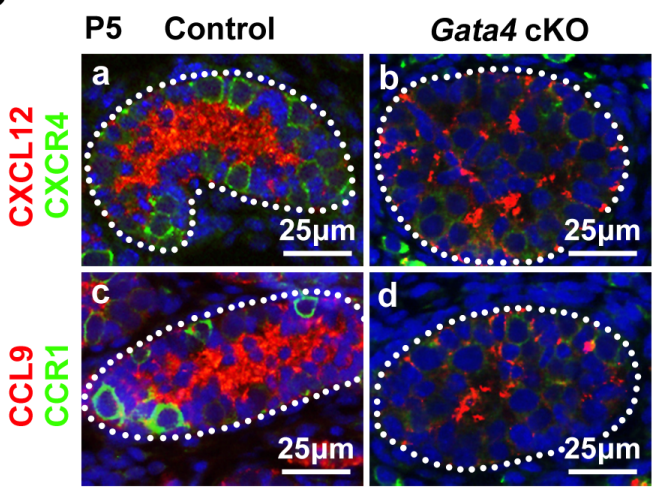

D

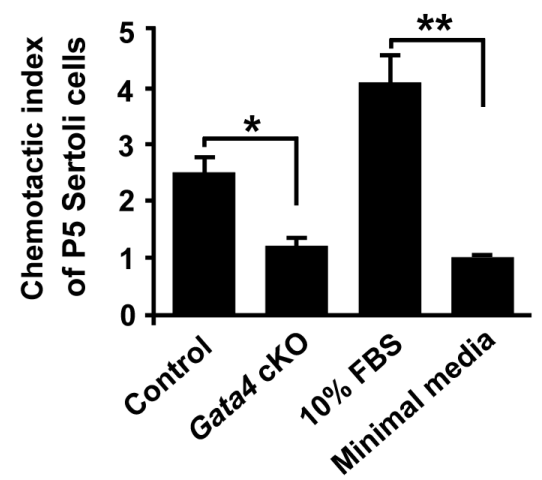

Figure 6: Identification of altered chemokine-related genes in Gata4 cKO testes at P5. A. A heat map analysis of control and Gata 4 cKO ( $n=3$ each) testes at P5. Geen and red represent low and high expression levels, respectively. B. RT-PCR analyses of the indicated genes in control and Gata $4 \mathrm{cKO}$ testes $(n=3 \mathrm{each})$ at P5. The numbers at the bottom represent the relative fold reduction measured via the density analysis. Wt 1 is a marker of Sertoli cells, and $M v h$ is a marker of germ cells. Gapdh served as the internal control gene. C. Representative images of immunofluorescent staining for CXCL12 (red) and CXCR4 (green) expression in cross-sections of testes from control (a) and Gata4 cKO (b) mice at P5. Expression of CCL9 (red) and CCR1 (green) within the tubules of control (c) and Gata4 cKO (d) testes at P5. DAPI was used to stain DNA. The white dotted lines indicate the testicular tubules. Scale bar: $25 \mu \mathrm{m}$. D. The ability of stem/progenitor spermatogonia to migrate toward Sertoli cells was expressed as the chemotactic index. The chemotactic index with respect to the $10 \%$ FBS positive control was approximately three-fold greater compared to the negative control. The chemotactic index of the Gata4-deficient Sertoli cells was not significantly different than that of the negative control, which corresponded to only minimal media. The data are expressed as the mean \pm S.D. ${ }^{*} p<0.05, * * p<0.01$. 
transfection, whereas these genes were significantly down-regulated by mutant plasmid transfection. The Wt1 gene was not regulated by GATA4; its expression was not markedly altered by transfection with the Gata4expressing adenovirus or the Gata4 ${ }^{\text {Cys294Ala }}$ plasmid (Figure 7D). We further showed that Cxcl12 (Cxcl12 Luc) and $C c l 9$ (Ccl9 Luc) tluciferase activity in TM4 cells transfected with GATA4 was increased approximately threefold and fourfold, respectively, compared to controltransfected cells (Figure 7E). Collectively, in Sertoli cells, GATA4 contributes to the establishment and maintenance of the spermatogonial progenitor niche by regulating the chemokine factors CXCL12 and CCL9.

\section{DISCUSSION}

Several lines of evidence suggest that the Sertoli cell-enriched transcription factor GATA4 is necessary during multiple stages of embryonic gonad development, including genital ridge formation [27], sex determination [18] and testicular differentiation [21]. Although a previous study indicated that GATA4 in Sertoli cells has a slight effect on spermatogenesis (a phenotype was observed after 2.5 months) [28], our results support a much earlier requirement for GATA4 in Sertoli cells in regulating the neonatal SSC niche. In this study, we generated and analyzed Sertoli cell-specific Gata4 knockout males and

A

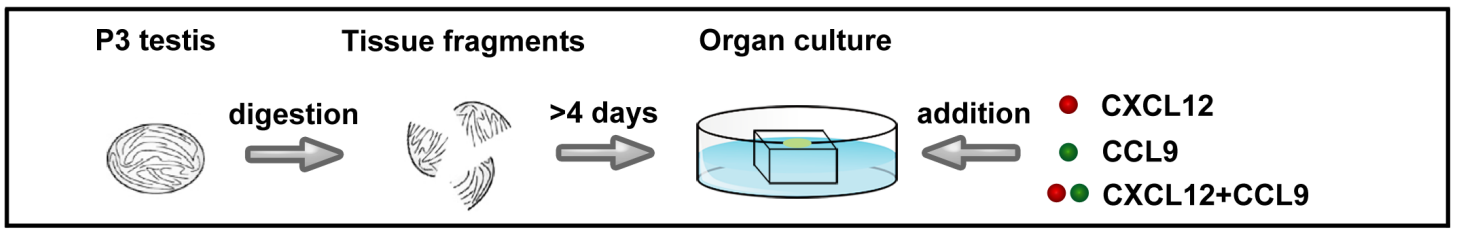

B

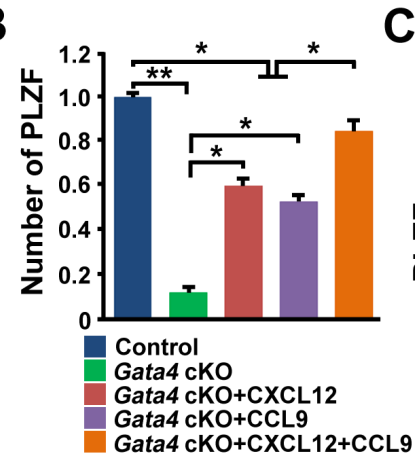

$\mathrm{C}$

D

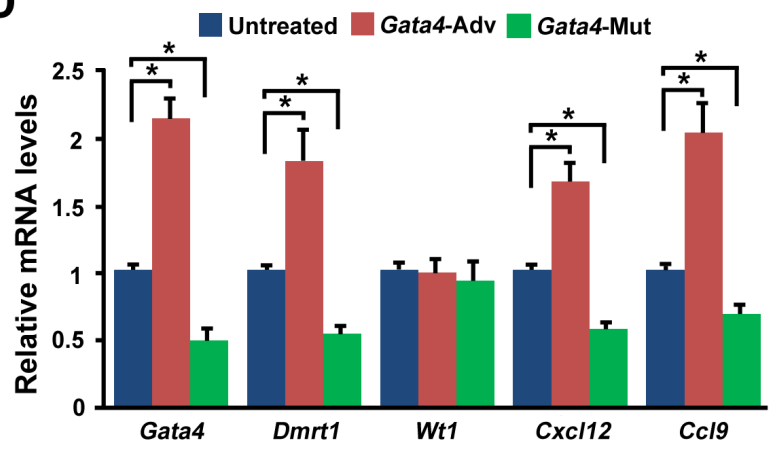

Gata4 cKO+CXCL12+CCL9

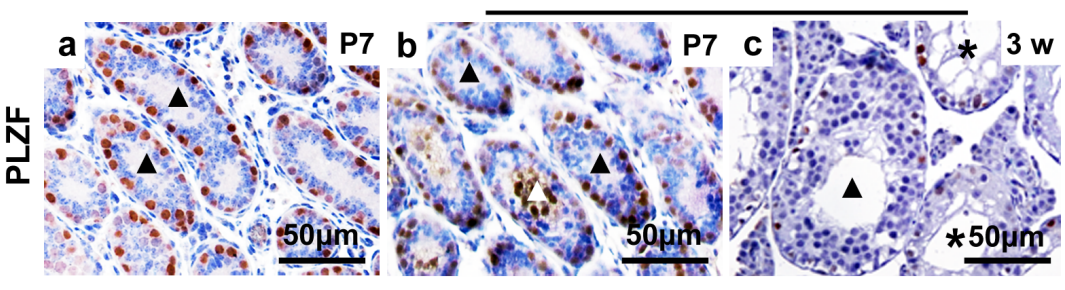

E

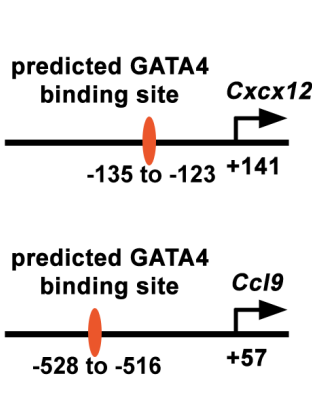

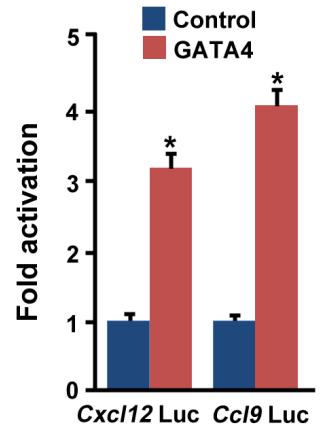

Figure 7: GATA4 regulates $\mathbf{C x c l 1 2}$ and $\boldsymbol{C c l 9}$ in Sertoli cells. A. Schematic of the in vitro testis tissue culture system and the chemokine rescue strategy. The tissue fragments of $\mathrm{P} 3$ testes were placed on an agarose gel that was half-soaked in the medium and cultured 4 or more days. CXCL12 and/or CCL9 (final concentration: $100 \mathrm{ng} / \mathrm{ml}$ ) were added to the culture medium. B. The relative number of $\mathrm{PLZF}^{+}$undifferentiated spermatogonia. Tissue fragments of $\mathrm{P} 3$ testes were cultured in vitro for 4 days, and $\mathrm{PLZF}^{+}$cells were counted in three random $250 \mu \mathrm{m} \times 250 \mu \mathrm{m}$ areas. The data are expressed as the mean \pm S.D ( $n=3$ per group). ${ }^{*} p<0.05$. C. A representative image of seminiferous tubule staining for PLZF (brown) after culture for 4 days (P7) (a: control; b: Gata 4 cKO) or 4 weeks (c: Gata 4 cKO). Black triangles in $\mathrm{a}$ and $\mathrm{b}$ indicate normal testicular tubules. The white triangle in $\mathrm{b}$ indicates a testicular tubule, where PLZF ${ }^{+}$spermatogonia remain aligned along the luminal side. The black triangle in c shows tubules with germ cells arrested as spermatocytes. The white stars in c indicate tubules devoid of germ cells. Scale bar, $50 \mu \mathrm{m}$. D. The relative mRNA levels of Gata4, Dmrt1, Wt1, Cxcl12 and Ccl9 in

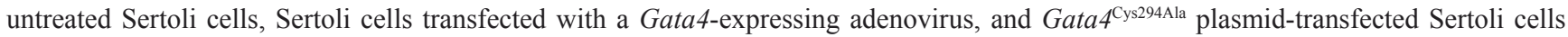
from P5 testes. The data are expressed as the mean \pm S.D. ${ }^{*} p<0.05$. E. TM4 cells were cotransfected with $C x c l 12$ Luc or Ccl9 Luc and PCB6+GATA4 or the control PCB6+ vector. The $\mathrm{Cxcl12}$ and $\mathrm{Ccl} 9$ promoters were both transactivated by GATA4. The data are present as the mean \pm SEM. $* p<0.05$. 
found that GATA4 deficiency compromised the size of the SSC pool, leading to a complete loss of germ cells, including SSCs. Spermatogenic failure occurred from P7 to 4 weeks in Gata 4 cKO males.

In the discussion, we focus on addressing three key issues: (i) the reason for the complete loss of germ cells by as early as the initial round of spermatogenesis in Gata4 cKO testes; (ii) the location and correction of the defect in Gata4 cKO testes; and (iii) the exploration of possible mechanisms by which GATA4 in Sertoli cells regulates the SSC niche.

In the first postnatal week, gonocytes directly give rise to differentiating spermatogonia and SSCs in parallel [2]. The first round of mouse spermatogenesis is initiated directly from gonocytes, without passing through SSCs. However, the subsequent rounds of spermatogenesis are derived from SSCs, which are required for continuous sperm production. We showed that neither the establishment nor the maintenance of the SSC pool was appropriately regulated in Gata 4 cKO testes (Figure 3). Meanwhile, the gonocyte-derived differentiating spermatogonia differentiated into meiotic spermatocytes and then underwent apoptosis (Figure 4). Thus, these two processes led to a complete loss of germ cells by the end of the initial wave of spermatogenesis in Gata $4 \mathrm{cKO}$ males (Figure 7E).

We also evaluated other potential abnormalities in Sertoli cells, such as apoptosis, proliferation, polarity and the androgen/estrogen environment. Protein levels of apoptotic markers (FasL and Bax) and proliferative markers (PCNA and Cyclin D3) were not significantly different in Sertoli cell lysates from control and Gata4 cKO testes (Figure S3). However, there were clear signs of Sertoli cell injury and defects in polarity in Gata4 cKO testes after 3 weeks of age, based on the presence of vacuoles and the adluminal location of Sertoli cells. To investigate whether the SSC pool maintenance failure was due to changes in the androgen and estrogen microenvironment in the seminiferous epithelium, we measured testicular testosterone and estradiol levels at puberty and found that these levels were not significantly different between control and Gata4 $\mathrm{cKO}$ mice (Figure $\mathrm{S} 4 \mathrm{~A})$. Furthermore, the expression of AR, ER $\alpha$ and ER $\beta$ was not obviously altered in testis lysates from control and Gata4 cKO mice (Figure S4B). In adult Gata4 cKO testes, interstitial cell hyperplasia was apparent. However, at this stage, Gata4 cKO testes were much smaller than control testes, and their weight was one-fifth that of control testes, suggesting that the apparent increase in interstitial cell number in any given section may be caused by the decrease in the total volume of the adult mutant testes.

Spermatogenesis is supported by an intimate interaction between germ cells and somatic Sertoli cells, which provides the essential microenvironment (niche) for functional spermatogenesis [29]. Disruption of spermatogenesis can therefore be caused by defects that affect either germ cells or Sertoli cells and the testicular environment. To determine the location of the defect (should be impaired Sertoli cell function) and to potentially correct this defect, testis germinal cells from Gata 4 cKO mice must be exposed to a normal testicular environment. As expected, testis germinal cells from P5 Gata 4 cKO males generated functional spermatozoa after exposure to $K i t^{\mathrm{W} / \mathrm{W}-\mathrm{v}}$ tubules, which represent a welldeveloped somatic cell environment, using transplantation technology (Figure 5). This manipulation rescued the infertile phenotype of the Gata $4 \mathrm{cKO}$ mice and provided new leads for the treatment of infertile patients carrying a GATA4 mutation.

CXCL12/CXCR4 chemokine signaling, which is essential for the maintenance of SSCs [9], was attenuated in P5 Gata4 cKO testes (Figure 6). Our microarray and RT-PCR data showed that the Fgf2 transcript was also significantly reduced in response to GATA4 knockout in Sertoli cells (Figure 6A, 6B and Table S3). Yoon KA et al. suggested that FGF2 stimulates SDF-1 (CXCL12) expression through the Erm transcription factor in TM4 Sertoli cells [30]. Thus, CXCL12/CXCR4 chemokine signaling would be further abated by FGF2 attenuation in Gata4 cKO Sertoli cells. Additional genes related to chemokine signaling that were significantly downregulated included $\mathrm{Ccl}$, $\mathrm{Ccr} 1, \mathrm{Ccl} 3, \mathrm{Xcll}$ and $\mathrm{Ccrl} 2$ (Figure 6A, 6B and Table S3). However, whether these chemokines or receptors are niche signaling molecules that regulate SSC self-renewal and maintenance remains to be determined using knockout mouse models (in vivo) or siRNA knockdowns in SSCs (in vitro). In addition to the attenuated expression of niche chemokine signaling molecules, the fatty acid metabolism pathway, which is indispensable for spermatogenesis, is also dysregulated in Gata 4 cKO testes. Fatty acid enzyme genes, such as Elovl2 [31], Fads 1/2 [32, 33], Scd1/2 [34] and Ppt1 [35], have been reported to be essential for spermatogenesis and Sertoli cell polarity. The transcription of Elovl2, Scd1 and Scd2 was down-regulated, whereas the Fads1 and Fads 2 transcripts were elevated in Gata 4 cKO testes (Tables S3 and S4). The down-regulation of two genes that encode Sertoli cell-secreted factors, Eppin and Nrg1, in Gata4 cKO testes is of particular interest, as mouse EPPIN is secreted by Sertoli cells and taken up by adjacent spermatogonia [36]. Neuregulin1 (NRG1) has only been found in Sertoli cells, and its receptor, ERBB4, localizes to the surface of spermatogonia and pre-spermatocytes [37]. Zhang et al. suggested that NRG1 promotes spermatogonia proliferation and meiotic initiation [38]. In addition, Rhox 5 [39], Wfdc10 [40], Mex3b [41], Art3 [42] and Tubb3 [43], which are involved in spermatogenesis, were up-regulated in P5 Gata4 cKO testes. However, the significance and mechanisms of action of these transcripts in relation to the SSC pool and spermatogenesis require further investigation. During the first wave of spermatogenesis, Gata4 cKO testes exhibited an extensive loss of germ 
cells, including spermatogonia. This phenotype is further supported by the fact that transcripts related to cellular apoptosis, such as Gpnmb [44], Naip5, Pxt1, Phlda1, Npvf, Igfbp3, Tbx3 and Aifm2, were up-regulated in P5 Gata4 cKO testes.

Our study suggested that the addition of CXCL12 and CCL9 to an in vitro testis tissue culture system increased the number of $\mathrm{PLZF}^{+}$undifferentiated spermatogonia in Gata 4 cKO testes. We performed q-PCR to determine whether the expression of the differentially expressed genes discovered in the microarray experiment could be corrected by CXCL12 and CCL9 treatment for 4 days. We randomly selected twenty Sertoli cellexpressed genes and showed that the mRNA levels of sixteen genes were significantly restored in chemokinetreated cKO testes (Figure S5). We could not exclude the possibility that other genes may be regulated by GATA4 in a chemokine-independent manner. Meanwhile, CXCL12 and CCL9 could not replace all of the functions of GATA4, but supplementation with CXCL12 and CCL9 did increase the number of $\mathrm{PLZF}^{+}$undifferentiated spermatogonia. In fact, seminiferous tubules of chemokine-treated Gata4 cKO testes either contained germ cells arrested as spermatocytes or were devoid of germ cells after 4 weeks in culture (Figure 7C).

Another group reported that GATA4 regulates Sertoli cell function and plays a role in fertility in adult male mice using the anti-Müllerian hormone receptor type 2 (Amhr2)-Cre system [28]. In their study, Gata $4^{\text {flox }}$ flox, Amhr2-Cre mice developed age-dependent Sertoli cell vacuolation, exhibited increased permeability of the blood-testis barrier, and showed a loss of fertility after 2.5 months. However, in our Gata4 $4^{\text {flox/lox }}$ Amh-Cre model, a complete loss of germ cells, including spermatogonia, occurred as early as 3 weeks (Figure 2). Differences between the Amhr2-Cre and Amh-Cre systems may account for these discrepant conclusions. Amhr2-Cre knock-in mice have been reported to exhibit Cre activity exclusively within the Müllerian duct mesenchyme at E12.5 $[45,46]$ and in postnatal ovarian granulosa cells [47, 48] and uterine epithelial cells [49]. Accordingly, the role of GATA4 expression in Sertoli cells in testicular development cannot be conclusively ascertained from the Gata4 ${ }^{\text {flox/flox }}, A m h r 2-C r e$ model due to the non-specificity and inefficiency of Amhr2-Cre within Sertoli cells. In contrast, numerous studies have demonstrated that $\mathrm{Amh}$ Cre models exhibit Cre activity in Sertoli cells after E14.5 [50-54].

In summary, we found that Sertoli cell-specific Gata4 knockout males exhibited an extensive loss of germ cells, including spermatogonia, during the initial waves of spermatogenesis. Our results further demonstrated that GATA4 plays a critical role in the regulation of the Sertoli cell-promoted SSC niche via the transcriptional regulation of chemokine signals.

\section{MATERIALS AND METHODS}

\section{Experimental animals}

Gata $4^{\text {flox fllox }}$ mice homozygous for a floxp allele of Gata4, Amh-Cre were used in the present study, which have been described previously [50, 53, 55]. Exons 3-5 of the Gata4 gene was left flanked by single loxP sites after the floxed neo cassette was excised by the in vivo expression of $\mathrm{Cre}$ recombinase. Gata4-conditional mutants and littermate controls were obtained by crossing Gata $^{\text {flox/flox }}$ and Gata4 $4^{\text {flox } /+}$, Amh-Cre mice. Genotyping was performed using PCR, as described previously [53, 55]. The primer sequences are provided in Table S1. For fertility testing, 6- to 8-week old Gata $4^{\text {flox fllox }}$ (control) and Gata4 cKO males ( $n=10$ each) were separately housed with wild-type C57BL/6 females for 3 months, and the pregnancy rate (\%) was assessed. Serum and testicular testosterone (T) and estradiol (E2) concentrations were measured with a previously described tritium-based radioimmunoassay (RIA) assay [56]. All experimental protocols and animal handling procedures were conducted in accordance with the guidelines and procedures approved by the Institutional Animal Care Committee of Institute of Zoology (IOZ), University of Chinese Academy of Sciences (UCAS).

\section{Histological examination and immunostaining}

The control and Gata4 cKO male mice were euthanized via cervical dislocation and the testes were immediately fixed in Bouin's solution for hematoxylin and eosin (H\&E) staining or in $4 \%$ formaldehyde (PFA) in PBS for immunostaining, as previously described [57-59]. In brief, tissue sections were deparaffinized and rehydrated, followed by antigen retrieval in 10 $\mathrm{mM}$ sodium citrate buffer. For immunohistochemistry (IHC), the sections were blocked with $5 \%$ bovine serum albumin (BSA) and incubated with the primary antibody at $4{ }^{\circ} \mathrm{C}$ overnight, and then the secondary antibody was applied for 1 hour. Staining was visualized using a DAB substrate kit (Zhongshan Technology, Beijing, China). For immunofluorescence (IF), the sections were blocked using a blocking buffer (donkey serum, 0.3\% Triton $\mathrm{X}-100$ in PBS) and incubated with primary antibodies overnight at $4^{\circ} \mathrm{C}$. Sections were washed and incubated with FITC or TRITC-conjugated secondary antibodies (Jackson ImmunoResearch, CA, USA) for 1 hour and counterstained with DAPI (Sigma, MO, USA) to identify the nuclei. The primary and secondary antibodies used for immunostaining are listed in Table S2. 


\section{Whole-mount seminiferous tubule staining}

P7 mouse testes were dissected to remove the tunica albuginea, and seminiferous tubules were untangled using forceps. Whole-mount immunofluorescence staining was performed, as described previously [60]. Stained tubules were spread on glass slides and imaged. Primary and secondary antibodies used for whole-mount seminiferous tubule IF are listed in Table S2.

\section{BrdU incorporation assay}

BrdU labeling and detection were conducted, as previously described [27]. Briefly, mice were injected intraperitoneally (i.p.) with $100 \mathrm{mg} / \mathrm{kg}$ body weight of BrdU (Sigma, MO, USA) 4 hours before sacrifice. The testes were then removed and processed for whole-mount seminiferous tubule staining. A purified mouse anti-BrdU monoclonal antibody (BD Bioscience, CA, USA) was used for BrdU detection. To determine the percentage of GFRa ${ }^{+}$SSCs that were positive for BrdU, we counted the $\mathrm{GFRa}^{+} \mathrm{SSCs}$ in at least two $10 \mathrm{~mm}$-length seminiferous tubules.

\section{Western blot}

Western blot analysis was performed as described previously [58]. The proteins were electrophoresed under reducing conditions in 12\% SDS-PAGE gels and transferred to nitrocellulose membranes. The blots were blocked in $5 \% \mathrm{BSA}$ and incubated overnight at $4{ }^{\circ} \mathrm{C}$ with the primary antibody, followed by incubation with the secondary antibody for 1 hour at room temperature. The primary and secondary antibodies used for the Western blot are listed in Table S2. The specific signals and the corresponding band intensities were evaluated using an Odyssey Infrared Imaging system and software (LI-COR Bioscience, NE, USA).

\section{Analysis of apoptotic cells}

A TUNEL assay was conducted using an In Situ Cell Death Detection Kit (Promega, CA, USA), as recommended [61]. Sections were counterstained with DAPI to identify the nuclei.

\section{Germinal cell transplantation}

Control and Gata4 cKO male pups from the same litter were used as donor animals. Germinal cells for transplantation are obtained from the testes of mice 5 days after birth via a two-step enzymatic digestion protocol [62]. The cells were suspended in Dulbecco's modified
Eagle's medium (containing 10\% fetal bovine serum, 6 $\mathrm{mM}$ glutamine, $6 \mathrm{mM}$ lactate, $0.5 \mathrm{mM}$ pyruvate, $30 \mathrm{mg} / \mathrm{l}$ penicillin, $50 \mathrm{mg} / 1$ streptomycin and $0.03 \%$ trypan blue) at a final concentration of $10^{7}$ cells $/ \mathrm{ml}$. The cell suspension $(\sim 10 \mu \mathrm{l})$ was injected into the seminiferous tubules of $K_{i t}{ }^{\mathrm{W} / \mathrm{Wv}_{\mathrm{v}}}$ recipient males (The Jackson Laboratory, ME, USA) via the rete testis, the testis were replaced, and the animals were allowed to recover. Eight weeks after transplantation, the recipient mouse testes were harvested for immunofluorescence. Spermatozoa from transplanted recipient $\mathrm{Kit}^{\mathrm{W} / \mathrm{Wv}}$ males were microinjected into oocytes derived from $\mathrm{C} 57 \mathrm{BL} / 6$ female mice using a piezoelectric actuator (PrimeTech, Ibaraki, Japan). The injected oocytes were cultured and transferred to the oviducts of D1 pseudopregnant ICR female mice.

\section{Neonatal testis tissue culture}

The testes from P3 control and Gata4 cKO males were decapsulated and gently cut into several pieces 1-3 $\mathrm{mm}$ in diameter. The testis explants were cultured, as described by Sato et al. [63]. Briefly, $1.5 \%$ (w/v) agarose gel stands $(10 \times 10 \times 5 \mathrm{~mm}$ in size and placed in six-well plates) were incubated with the culture medium for more than 24 hours. The testis explants were placed at the medium-air interface on each agarose gel stand and cultured at $33^{\circ} \mathrm{C}$ in $5 \% \mathrm{CO}_{2}$. The medium was added to CXCL12 (GenScript, NJ, USA), CCL9 (GenScript, NJ, USA), both CXCL12 and CCL9 (final concentration $=100$ $\mathrm{ng} / \mathrm{ml}$ ), or the vehicle control. The culture medium was replaced every 2 days. The testis explants were collected 4 days or 4 weeks later and fixed in 4\% PFA.

\section{Sertoli cell isolation, culture and transfection}

A modified previously described method was used to isolate the Sertoli cells from the testes of P5 mice $[58,64]$. Briefly, the seminiferous tubules were pooled and washed with $1 \times \mathrm{PBS}$ thrice and incubated with 1 $\mathrm{mg} / \mathrm{ml}$ collagenase IV (Sigma, MO, USA), $1 \mathrm{mg} / \mathrm{ml}$ of hyaluronidase (Sigma, MO, USA) and $0.5 \mathrm{mg} / \mathrm{ml}$ DNase I (Sigma, MO, USA) in DMEM/F12 medium (HyClone, MO, USA) for 5 minutes at $37^{\circ} \mathrm{C}$ in a shaker. These dispersed cells were then washed twice with DMEM/ F12 medium and placed into culture dishes in DMEM/ F12 containing 10\% fetal bovine serum (FBS) (HyClone, $\mathrm{MO}$, USA) and were incubated at $37^{\circ} \mathrm{C}$ in $5 \% \mathrm{CO}_{2}$. After 1 day of culture, the cells were treated with a hypotonic solution (20 mM Tris, $\mathrm{pH}$ 7.4) for 1 minute to remove the remaining germ cells. The GATA4 expression vector containing the Cys294Ala was generated via site-directed mutagenesis of the Gata4-pEGFP-N1 plasmid using a QuikChange II Site-Directed Mutagenesis Kit (Stratagene, CA, USA), according to the manufacturer's protocol. The CMV-Gata4 adenovirus (Seven Hills Bioreagents, CA, 
USA) and the GATA4 binding site (Cys294Ala) mutant plasmid were used to transfect the Sertoli cells.

\section{Chemotaxis assays}

Chemotaxis assays were performed using $8-\mu \mathrm{m}$ pore Cytoselect 24-well assay plates (Cell Biolabs, CA, USA), according to a previous report [11]. The Sertoli cells isolated from the P5 control and the Gata $4 \mathrm{cKO}$ testes were seeded at a concentration of $2.5 \times 10^{5}$ cells in the lower chambers of the transwell units and cultured in minimal media for 48 hours prior to the migration assays. Control spermatogonial progenitors (or other germ cells) from 5-day-old testes were seeded in minimal media in the upper chamber at a concentration of $5 \times 10^{5}$ cells. The cells were allowed to migrate for 24 hours at $34^{\circ} \mathrm{C}, 5 \%$ $\mathrm{CO}_{2}$, and maximum humidity. DMEM/F12 with $10 \%$ FBS was used as a positive control in the lower chamber for all experiments, and minimal media alone, without any added cells or serum, was used as a negative control. The chemotactic index is defined as the density measurement of the migrated stem/progenitor spermatogonia compared to the negative control.

\section{Expression profiling}

Testes were dissected from the P5 control and Gata4 cKO mice ( $n=3$ each group) and immediately homogenized in $1 \mathrm{ml}$ Tripure (Roche, Shanghai, China). Total RNA was extracted separately using an RNeasy kit (Qiagen, Suzhou, China). RNA (10 $\mu \mathrm{g})$ was pooled, and biotinylated cRNA target was independently generated from each pool. Each cRNA was hybridized to an Affymetrix U74Av2 Murine Genome Array. A microarray analysis was performed by Beijing Yuanquanyike Biological Technology Co., LTD (Beijing, China). Screening of differentially expressed genes (up-regulation and down-regulation ) were set to $\log 2 \mid$ Fold change $\mid \geq 1$ and a $P$-value $<0.05$ and are listed in Table S3 and 4.

\section{Quantitative RT-PCR}

RNA was extracted from the P5 testes using Trizol (Invitrogen, TX, USA) according to the manufacturer's protocol. RNA samples were subjected to reverse transcription using a PrimeScript RT reagent Kit (Takara, Dalian, China). The reactions were run in triplicate in three independent experiments. Samples CT values were normalized to the corresponding Gapdh CT values, and relative expression levels were calculated using the $\Delta \Delta C T$ method [65]. The primer sequences are provided in Table S1.

\section{Luciferase assay}

TM4 cells were grown in F12/DMEM supplemented with $10 \% \mathrm{FBS}$ at $37^{\circ} \mathrm{C}$ with $5 \% \mathrm{CO}_{2}$. The cells were seeded at a density of approximately 50000 cells/well in 12-well plates 12 hours before transfection. Mouse Gata4 cDNA was amplified by PCR using testis cDNA and subcloned into the PCB6+ vector. Promoters of Cxcll2 and Ccl9 were amplified by PCR from mouse genomic DNA and subcloned into the pGL3-basic luciferase reporter vector (Promega, CA, USA). The cells were cotransfected with expression plasmids and the luciferase reporter plasmid. The empty expression vector (PCB6+ plasmid) was cotransfected as an internal control to allow normalization for differences in transfection efficiency [66]. The transfection was performed with Lipofectamine 2000 (Invitrogen, TX, USA) according to the manufacturer's recommendations. The cells were harvested for the luciferase assays 36 hours after transfection.

\section{Statistical analysis}

Protein and mRNA levels, the pregnancy rate, the number of GFRa ${ }^{+} \mathrm{SSCs}$ per 1-mm seminiferous tubule, the percentage of GFRa1 ${ }^{+} \mathrm{SSCs}$ positive for $\mathrm{BrdU}$, and the chemotactic index between control and Gata4 cKO mice were analyzed using a Student's $t$-test. The results are presented as the mean \pm SEM. Statistical significance was considered for ${ }^{*} p<0.05$ and ${ }^{* *} p<0.01$.

\section{ACKOWLEDGMENTS}

We thank Xing-Xu Huang for providing Gata4+flox mice. This work was supported by NSFC (Natural Science Foundation of China) (31171380, 31471352, 31471400, 31501198), Major Research Plan (2011CB944302) and National Technology Support Project (2012DA113B08).

\section{CONFLICTS OF INTEREST}

The authors declare that they have no conflict of interest.

\section{REFERENCES}

1. Greenberg SH, Lipshultz LI, Wein AJ: Experience with 425 subfertile male patients. The Journal of urology 1978, 119:507-510.

2. Yoshida S, Sukeno M, Nakagawa T, Ohbo K, Nagamatsu G, Suda T, Nabeshima Y: The first round of mouse spermatogenesis is a distinctive program that lacks the self-renewing spermatogonia stage. Development 2006, 133:1495-1505. 
3. Bellve AR, Cavicchia JC, Millette CF, O'Brien DA, Bhatnagar YM, Dym M: Spermatogenic cells of the prepuberal mouse. Isolation and morphological characterization. The Journal of cell biology 1977, 74:6885.

4. Laiho A, Kotaja N, Gyenesei A, Sironen A: Transcriptome profiling of the murine testis during the first wave of spermatogenesis. PloS one 2013, 8:e61558.

5. Kramer JM, Erickson RP: Developmental program of PGK1 and PGK-2 isozymes in spermatogenic cells of the mouse: specific activities and rates of synthesis. Developmental biology 1981, 87:37-45.

6. Chen SR, Liu YX: Regulation of spermatogonial stem cell self-renewal and spermatocyte meiosis by Sertoli cell signaling. Reproduction 2015, 149:R159-R167.

7. Meng X, Lindahl M, Hyvonen ME, Parvinen M, de Rooij DG, Hess MW, Raatikainen-Ahokas A, Sainio K, Rauvala $\mathrm{H}$, Lakso $\mathrm{M}$ et al: Regulation of cell fate decision of undifferentiated spermatogonia by GDNF. Science 2000, 287:1489-1493.

8. Kubota H, Avarbock MR, Brinster RL: Growth factors essential for self-renewal and expansion of mouse spermatogonial stem cells. Proceedings of the National Academy of Sciences of the United States of America 2004, 101:16489-16494.

9. Yang QE, Kim D, Kaucher A, Oatley MJ, Oatley JM: CXCL12-CXCR4 signaling is required for the maintenance of mouse spermatogonial stem cells. Journal of cell science 2013, 126:1009-1020.

10. Chen C, Ouyang W, Grigura V, Zhou Q, Carnes K, Lim H, Zhao GQ, Arber S, Kurpios N, Murphy TL et al: ERM is required for transcriptional control of the spermatogonial stem cell niche. Nature 2005, 436:1030-1034.

11. Simon L, Ekman GC, Garcia T, Carnes K, Zhang Z, Murphy T, Murphy KM, Hess RA, Cooke PS, Hofmann $\mathrm{MC}$ : ETV5 regulates sertoli cell chemokines involved in mouse stem/progenitor spermatogonia maintenance. Stem cells 2010, 28:1882-1892.

12. Tremblay JJ, Viger RS: GATA factors differentially activate multiple gonadal promoters through conserved GATA regulatory elements. Endocrinology 2001, 142:977986.

13. Lindeboom F, Gillemans N, Karis A, Jaegle M, Meijer D, Grosveld F, Philipsen S: A tissue-specific knockout reveals that Gatal is not essential for Sertoli cell function in the mouse. Nucleic acids research 2003, 31:5405-5412.

14. Watt AJ, Zhao R, Li J, Duncan SA: Development of the mammalian liver and ventral pancreas is dependent on GATA4. BMC developmental biology 2007, 7:37

15. Molkentin JD, Lin Q, Duncan SA, Olson EN: Requirement of the transcription factor GATA4 for heart tube formation and ventral morphogenesis. Genes \& development 1997, 11:1061-1072.

16. Kuo CT, Morrisey EE, Anandappa R, Sigrist K, Lu MM,
Parmacek MS, Soudais C, Leiden JM: GATA4 transcription factor is required for ventral morphogenesis and heart tube formation. Genes \& development 1997, 11:1048-1060.

17. $\mathrm{Hu}$ YC, Okumura LM, Page DC: Gata4 is required for formation of the genital ridge in mice. PLoS genetics 2013, 9:e1003629.

18. Tevosian SG, Albrecht KH, Crispino JD, Fujiwara Y, Eicher EM, Orkin SH: Gonadal differentiation, sex determination and normal Sry expression in mice require direct interaction between transcription partners GATA4 and FOG2. Development 2002, 129:4627-4634.

19. Bouma GJ, Washburn LL, Albrecht KH, Eicher EM: Correct dosage of Fog2 and Gata4 transcription factors is critical for fetal testis development in mice. Proceedings of the National Academy of Sciences of the United States of America 2007, 104:14994-14999.

20. Miyamoto Y, Taniguchi H, Hamel F, Silversides DW, Viger RS: A GATA4/WT1 cooperation regulates transcription of genes required for mammalian sex determination and differentiation. BMC molecular biology 2008, 9:44.

21. Manuylov NL, Zhou B, Ma Q, Fox SC, Pu WT, Tevosian SG: Conditional ablation of Gata4 and Fog2 genes in mice reveals their distinct roles in mammalian sexual differentiation. Developmental biology 2011, 353:229-241.

22. Lourenco D, Brauner R, Rybczynska M, Nihoul-Fekete C, McElreavey K, Bashamboo A: Loss-of-function mutation in GATA4 causes anomalies of human testicular development. Proceedings of the National Academy of Sciences of the United States of America 2011, 108:1597-1602.

23. Bashamboo A, Brauner R, Bignon-Topalovic J, LortatJacob S, Karageorgou V, Lourenco D, Guffanti A, McElreavey K: Mutations in the FOG2/ZFPM2 gene are associated with anomalies of human testis determination. Human molecular genetics 2014, 23:3657-3665.

24. Nakagawa T, Sharma M, Nabeshima Y, Braun RE, Yoshida $\mathrm{S}$ : Functional hierarchy and reversibility within the murine spermatogenic stem cell compartment. Science 2010, 328:62-67.

25. Grasso M, Fuso A, Dovere L, de Rooij DG, Stefanini M, Boitani C, Vicini E: Distribution of GFRA1-expressing spermatogonia in adult mouse testis. Reproduction 2012, 143:325-332.

26. Suzuki H, Sada A, Yoshida S, Saga Y: The heterogeneity of spermatogonia is revealed by their topology and expression of marker proteins including the germ cell-specific proteins Nanos2 and Nanos3. Developmental biology 2009, 336:222-231.

27. Hu YC, de Rooij DG, Page DC: Tumor suppressor gene Rb is required for self-renewal of spermatogonial stem cells in mice. Proceedings of the National Academy of Sciences of the United States of America 2013, 110:12685-12690.

28. Kyronlahti A, Euler R, Bielinska M, Schoeller EL, Moley KH, Toppari J, Heikinheimo M, Wilson DB: GATA4 regulates Sertoli cell function and fertility in adult male 
mice. Molecular and cellular endocrinology 2011, 333:8595.

29. Ogawa T, Dobrinski I, Avarbock MR, Brinster RL: Transplantation of male germ line stem cells restores fertility in infertile mice. Nature medicine 2000, 6:29-34.

30. Yoon KA, Chae YM, Cho JY: FGF2 stimulates SDF-1 expression through the Erm transcription factor in Sertoli cells. Journal of cellular physiology 2009, 220:245-256.

31. Zadravec D, Tvrdik P, Guillou H, Haslam R, Kobayashi T, Napier JA, Capecchi MR, Jacobsson A: ELOVL2 controls the level of n-6 28:5 and 30:5 fatty acids in testis, a prerequisite for male fertility and sperm maturation in mice. Journal of lipid research 2011, 52:245-255.

32. Casado ME, Pastor O, Mariscal P, Canfran-Duque A, Martinez-Botas J, Kraemer FB, Lasuncion MA, MartinHidalgo A, Busto R: Hormone-sensitive lipase deficiency disturbs the fatty acid composition of mouse testis. Prostaglandins, leukotrienes, and essential fatty acids 2013, 88:227-233.

33. Stoffel W, Holz B, Jenke B, Binczek E, Gunter RH, Kiss C, Karakesisoglou I, Thevis M, Weber AA, Arnhold S et al: Delta6-desaturase (FADS2) deficiency unveils the role of omega3- and omega6-polyunsaturated fatty acids. The EMBO journal 2008, 27(17):2281-2292.

34. Saether T, Tran TN, Rootwelt H, Christophersen BO, Haugen TB: Expression and regulation of delta5-desaturase, delta6-desaturase, stearoyl-coenzyme A ( $\mathrm{CoA})$ desaturase 1 , and stearoyl-CoA desaturase 2 in rat testis. Biology of reproduction 2003, 69:117-124.

35. Boyer A, Lussier JG, Sinclair AH, McClive PJ, Silversides DW: Pre-sertoli specific gene expression profiling reveals differential expression of Ppt1 and Brd3 genes within the mouse genital ridge at the time of sex determination. Biology of reproduction 2004, 71:820-827.

36. Long Y, Gu A, Yang H, Ji G, Han X, Song L, Wang S, Wang X: Distribution of Eppin in mouse and human testis. Molecular medicine reports 2011, 4:71-75.

37. Falls DL: Neuregulins: functions, forms, and signaling strategies. Experimental cell research 2003, 284:14-30.

38. Zhang J, Eto K, Honmyou A, Nakao K, Kiyonari H, Abe S: Neuregulins are essential for spermatogonial proliferation and meiotic initiation in neonatal mouse testis. Development 2011, 138:3159-3168.

39. Maclean JA, 2nd, Chen MA, Wayne CM, Bruce SR, Rao M, Meistrich ML, Macleod C, Wilkinson MF: Rhox: a new homeobox gene cluster. Cell 2005, 120:369-382.

40. Zhou W, Bolden-Tiller OU, Shetty G, Shao SH, Weng CC, Pakarinen P, Liu Z, Stivers DN, Meistrich ML: Changes in gene expression in somatic cells of rat testes resulting from hormonal modulation and radiation-induced germ cell depletion. Biology of reproduction 2010, 82:54-65.

41. Irving TC, Millman BM: Changes in thick filament structure during compression of the filament lattice in relaxed frog sartorius muscle. Journal of muscle research and cell motility 1989, 10:385-394.

42. Okada H, Tajima A, Shichiri K, Tanaka A, Tanaka K, Inoue I: Genome-wide expression of azoospermia testes demonstrates a specific profile and implicates ART3 in genetic susceptibility. PLoS genetics 2008, 4:e26.

43. De Gendt K, Denolet E, Willems A, Daniels VW, Clinckemalie L, Denayer S, Wilkinson MF, Claessens F, Swinnen JV, Verhoeven G: Expression of Tubb3, a betatubulin isotype, is regulated by androgens in mouse and rat Sertoli cells. Biology of reproduction 2011, 85:934-945.

44. Yu W, Zheng H, Lin W, Tajima A, Zhang Y, Zhang $\mathrm{X}$, Zhang H, Wu J, Han D, Rahman NA et al: Estrogen promotes Leydig cell engulfment by macrophages in male infertility. The Journal of clinical investigation 2014, 124:2709-2721.

45. Jamin SP, Arango NA, Mishina Y, Hanks MC, Behringer RR: Requirement of Bmprla for Mullerian duct regression during male sexual development. Nature genetics 2002, 32:408-410.

46. Stewart CA, Wang Y, Bonilla-Claudio M, Martin JF, Gonzalez G, Taketo MM, Behringer RR: CTNNB1 in mesenchyme regulates epithelial cell differentiation during Mullerian duct and postnatal uterine development. Molecular endocrinology 2013, 27:1442-1454.

47. Robker RL, Watson LN, Robertson SA, Dunning KR, McLaughlin EA, Russell DL: Identification of sites of STAT3 action in the female reproductive tract through conditional gene deletion. PloS one 2014, 9:e101182.

48. Yu C, Zhang YL, Fan HY: Selective Smad4 knockout in ovarian preovulatory follicles results in multiple defects in ovulation. Molecular endocrinology 2013, 27:966-978.

49. Gao Y, Li S, Li Q: Uterine epithelial cell proliferation and endometrial hyperplasia: evidence from a mouse model. Molecular human reproduction 2014, 20:776-786.

50. Chen SR, Chen M, Wang XN, Zhang J, Wen Q, Ji SY, Zheng QS, Gao F, Liu YX: The Wilms tumor gene, $\mathrm{Wt1}$, maintains testicular cord integrity by regulating the expression of Col4a1 and Col4a2. Biology of reproduction 2013, 88:56.

51. Kim GJ, Georg I, Scherthan H, Merkenschlager M, Guillou F, Scherer G, Barrionuevo F: Dicer is required for Sertoli cell function and survival. The International journal of developmental biology 2010, 54:867-875.

52. Barrionuevo F, Georg I, Scherthan H, Lecureuil C, Guillou F, Wegner M, Scherer G: Testis cord differentiation after the sex determination stage is independent of Sox 9 but fails in the combined absence of Sox9 and Sox8. Developmental biology 2009, 327:301-312.

53. Lecureuil C, Fontaine I, Crepieux P, Guillou F: Sertoli and granulosa cell-specific Cre recombinase activity in transgenic mice. Genesis 2002, 33:114-118.

54. Garcia TX, Farmaha JK, Kow S, Hofmann MC: RBPJ in mouse Sertoli cells is required for proper regulation of the testis stem cell niche. Development 2014, 141:4468-4478. 
55. Watt AJ, Battle MA, Li J, Duncan SA: GATA4 is essential for formation of the proepicardium and regulates cardiogenesis. Proceedings of the National Academy of Sciences of the United States of America 2004, 101:1257312578 .

56. Akingbemi BT, Ge R, Klinefelter GR, Zirkin BR, Hardy MP: Phthalate-induced Leydig cell hyperplasia is associated with multiple endocrine disturbances. Proceedings of the National Academy of Sciences of the United States of America 2004, 101:775-780.

57. Chen SR, Zheng QS, Zhang Y, Gao F, Liu YX: Disruption of genital ridge development causes aberrant primordial germ cell proliferation but does not affect their directional migration. BMC biology 2013, 11:22.

58. Li XX, Chen SR, Shen B, Yang JL, Ji SY, Wen Q, Zheng QS, Li L, Zhang J, Hu ZY et al: The Heat-Induced Reversible Change in the Blood-Testis Barrier (BTB) Is Regulated by the Androgen Receptor (AR) via the Partitioning-Defective Protein (Par) Polarity Complex in the Mouse. Biology of reproduction 2013.

59. Lokman NA, Elder AS, Ween MP, Pyragius CE, Hoffmann $\mathrm{P}$, Oehler MK, Ricciardelli C: Annexin A2 is regulated by ovarian cancer-peritoneal cell interactions and promotes metastasis. Oncotarget 2013, 4:1199-1211.

60. Buganim Y, Itskovich E, Hu YC, Cheng AW, Ganz K, Sarkar S, Fu D, Welstead GG, Page DC, Jaenisch R: Direct reprogramming of fibroblasts into embryonic Sertoli-like cells by defined factors. Cell stem cell 2012, 11:373-386.

61. Fukuhara S, Chang I, Mitsui Y, Chiyomaru T, Yamamura S, Majid S, Saini S, Hirata H, Deng G, Gill A et al: DNA mismatch repair gene MLH1 induces apoptosis in prostate cancer cells. Oncotarget 2014, 5:11297-11307.

62. Ogawa T, Arechaga JM, Avarbock MR, Brinster RL: Transplantation of testis germinal cells into mouse seminiferous tubules. The International journal of developmental biology 1997, 41:111-122.

63. Sato T, Katagiri K, Gohbara A, Inoue K, Ogonuki N, Ogura A, Kubota Y, Ogawa T: In vitro production of functional sperm in cultured neonatal mouse testes. Nature 2011, 471:504-507.

64. Chang YF, Lee-Chang JS, Panneerdoss S, MacLean JA, 2nd, Rao MK: Isolation of Sertoli, Leydig, and spermatogenic cells from the mouse testis. BioTechniques 2011, 51:341-342, 344.

65. Hart JR, Roberts TC, Weinberg MS, Morris KV, Vogt PK: MYC regulates the non-coding transcriptome. Oncotarget 2014, 5:12543-12554.

66. Liu X, Yang WT, Zheng PS: Msi1 promotes tumor growth and cell proliferation by targeting cell cycle checkpoint proteins p21, p27 and p53 in cervical carcinomas. Oncotarget 2014, 5:10870-10885. 